\title{
Development and impact of arrhythmias after the Norwood procedure: A report from the Pediatric Heart Network
}

\author{
Matthew E. Oster, MD, MPH, ${ }^{\mathrm{a}}$ Shan Chen, MS, ${ }^{\mathrm{b}}$ Nicholas Dagincourt, MS, ${ }^{\mathrm{b}}$ Yaniv Bar-Cohen, MD, \\ Matthew Brothers, MD, ${ }^{\mathrm{a}}$ Nicole Cain, MD, ${ }^{\mathrm{d}}$ Steven D. Colan, MD, ${ }^{\mathrm{e}}$ Richard J. Czosek, MD, ${ }^{\mathrm{f}}$

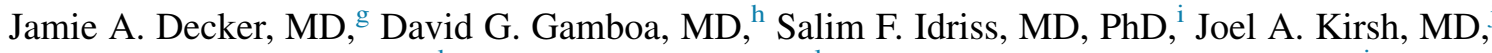 \\ Martin J. LaPage, MD, MS, ${ }^{\mathrm{k}}$ Richard G. Ohye, MD, ${ }^{l}$ Elizabeth Radojewski, RN, CCRP, \\ Maully Shah, MBBS, ${ }^{m}$ Eric S. Silver, MD, ${ }^{\mathrm{n}}$ Anoop K. Singh, MB, BCh, ${ }^{\circ}$ Joel D. Temple, MD, \\ John Triedman, MD, ${ }^{e}$ and Jonathan R. Kaltman, MD, ${ }^{\mathrm{q}}$ for the Pediatric Heart Network Investigators
}

\section{ABSTRACT}

Objectives: The study objective was to determine the predictors of new-onset arrhythmia among infants with single-ventricle anomalies during the postNorwood hospitalization and the association of those arrhythmias with postoperative outcomes (ventilator time and length of stay) and interstage mortality.

Methods: After excluding patients with preoperative arrhythmias, we used data from the Pediatric Heart Network Single Ventricle Reconstruction Trial to identify risk factors for tachyarrhythmias (atrial fibrillation, atrial flutter, supraventricular tachycardia, junctional ectopic tachycardia, and ventricular tachycardia) and atrioventricular block (second or third degree) among 544 eligible patients. We then determined the association of arrhythmia with outcomes during the post-Norwood hospitalization and interstage period, adjusting for identified risk factors and previously published factors.

Results: Tachyarrhythmias were noted in $20 \%$ of subjects, and atrioventricular block was noted in $4 \%$ of subjects. Potentially significant risk factors for tachyarrhythmia included the presence of modified Blalock-Taussig shunt $(P=.08)$ and age at Norwood ( $P=.07$, with risk decreasing each day at age 8-20 days); the only significant risk factor for atrioventricular block was undergoing a concomitant procedure at the time of the $\operatorname{Norwood}(P=.001)$, with the greatest risk being in those undergoing a tricuspid valve procedure. Both tachyarrhythmias and atrioventricular block were associated with longer ventilation time and length of stay $(P<.001$ for all analyses). Tachyarrhythmias were not associated with interstage mortality; atrioventricular block was associated with mortality among those without a pacemaker in the unadjusted analysis (hazard ratio, $2.3 ; P=.02$ ), but not after adding covariates.

Conclusions: Tachyarrhythmias are common after the Norwood procedure, but atrioventricular block may portend a greater risk for interstage mortality. ( $\mathrm{J}$ Thorac Cardiovasc Surg 2017;153:638-45)

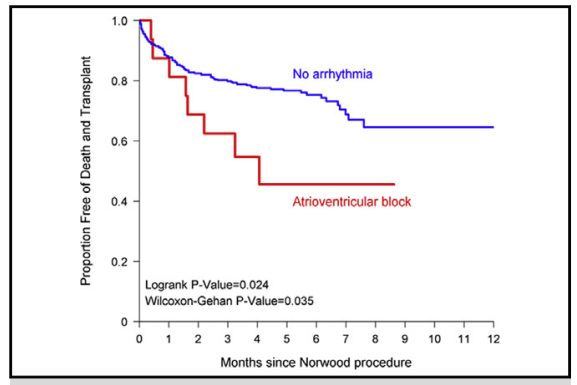

Atrioventricular block, but not tachyarrhythmia, is associated with increased mortality after the Norwood procedure.

\section{Central Message}

Patients with arrhythmias may have increased morbidity after the Norwood procedure, and those with atrioventricular block have increased intermediate-term mortality.

\section{Perspective}

Arrhythmias are common after the Norwood procedure, but the risk factors for the development of arrhythmias and the impact of arrhythmias are unknown. The potential risk factors can help identify patients who may be at higher risk of developing arrhythmias, and the findings regarding morbidity and mortality among those with arrhythmias may help identify patients at greater risk of poor outcomes.

See Editorial Commentary page 646.

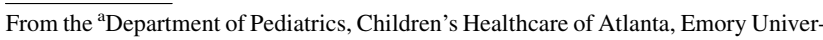
sity School of Medicine, Atlanta, Ga; ${ }^{b}$ New England Research Institutes, Watertown; 'Division of Pediatric Cardiology, Department of Pediatrics, Children's Hospital Los Angeles, Los Angeles, Calif; ${ }^{\mathrm{d}}$ Department of Pediatrics, Medical University of South Carolina, Charleston, SC; ${ }^{e}$ Department of Cardiology, Boston Children's Hospital, Boston, Mass; ${ }^{\mathrm{f}}$ Division of Pediatric Cardiology, Department of Pediatrics, The Heart Center, Cincinnati Children's Hospital Medical Center, Cincinnati, Ohio; ' Department of Pediatrics, Johns Hopkins All Children's Heart

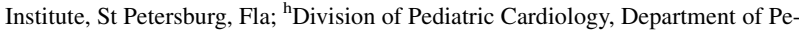
diatrics, University of Utah, Salt Lake City, Utah; ${ }^{\mathrm{i}}$ Division of Pediatric Cardiology, Department of Pediatrics, Duke University Medical Center, Durham, NC; ${ }^{\mathrm{j}}$ Department of Paediatrics \& Labatt Family Heart Centre, Hospital for Sick Children \& University of Toronto, Toronto, Ontario; ${ }^{k}$ Division of Pediatric Cardiology, Department of Pediatrics and Communicable Diseases, University of Michigan; ${ }^{\mathrm{l}}$ Department of Pediatrics, University of Michigan Medical School, Ann Arbor, Mich; ${ }^{\mathrm{m}}$ Department of Pediatrics, Children's Hospital of Philadelphia, Philadelphia, Pa; ${ }^{\mathrm{n}}$ Division of Pediatrics, Columbia University Medical Center, New York, NY; ${ }^{\circ}$ Department of Pediatrics, Children's Hospital of Wisconsin, Milwau-

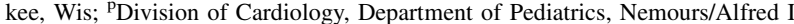
duPont Hospital for Children Wilmington, Del; and ${ }^{\mathrm{q}}$ Division of Cardiovascular Sciences, The National Heart, Lung, and Blood Institute, National Institutes of Health, Bethesda, Md.

This work was supported by HL068269, HL068270, HL068279, HL068281, HL068285, HL068292, HL068290, HL068288, HL085057, HL109781, and HL109737 from the National Heart, Lung, and Blood Institute. The views expressed are those of the authors and do not necessarily reflect official National Heart, Lung, and Blood Institute or National Institutes of Health positions. Clinical Trial Registration Information: www.ClinicalTrials.gov Identifier: NCT00115934. Received for publication April 14, 2016; revisions received Oct 18, 2016; accepted for publication Oct 19, 2016; available ahead of print Dec 7, 2016

Address for reprints: Matthew E. Oster, MD, MPH, 2835 Brandywine Rd, Ste 300, Atlanta, GA 30341 (E-mail: osterm@kidsheart.com).

$0022-5223 / \$ 36.00$

Copyright (c) 2016 by The American Association for Thoracic Surgery http://dx.doi.org/10.1016/j.jtcvs.2016.10.078 


\section{Abbreviations and Acronyms}

CI = confidence interval

MBTS $=$ modified Blalock-Taussig shunt

RVPAS = right ventricle-to-pulmonary artery shunt

SVR $=$ Single Ventricle Reconstruction

Scanning this QR code will take you to the appendices and video for this article.

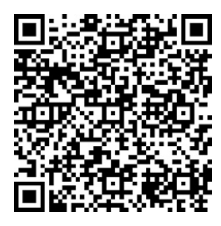

Over the past 40 years, survival for the Norwood procedure and staged reconstruction for infants with hypoplastic left heart syndrome and related single right ventricle anomalies have dramatically improved. ${ }^{1-3}$ What was once a universally fatal disease in infancy is now a disease in which transplant-free survival to 1 year of age is $68 \%{ }^{4}$ However, with this improved survival comes an increased recognition of and focus on morbidity. One important aspect of morbidity in this population is the prevalence of arrhythmias.

Although arrhythmias have been well studied in patients with single ventricle congenital heart disease who have survived the Fontan procedure, ${ }^{5-10}$ the prevalence and impact of arrhythmias after the Norwood procedure are not well known. Most prior studies of arrhythmias in infants with congenital heart disease have included a variety of operations, ${ }^{11-14}$ thus limiting the knowledge that is specific to those with single ventricle physiology after the Norwood procedure. One prior study from the Pediatric Heart Network Single Ventricle Reconstruction (SVR) Trial did examine some outcomes in those with arrhythmias: A total of 13 of 544 patients were noted to have perioperative second- or third-degree atrioventricular block in the intensive care unit on the day of the Norwood procedure, with heart block being associated with the development of renal failure, hepatic failure, and mediastinitis. ${ }^{15}$ This study did not examine the risk factors for the development of atrioventricular block or the interstage outcomes for those with atrioventricular block, and it did not examine any aspects of tachyarrhythmias.

With this limited knowledge regarding the development and impact of tachyarrhythmias and atrioventricular block in infants with single ventricle physiology, we examined data from the SVR Trial in an effort to
(1) determine the predictors of new-onset arrhythmia during the postoperative period after the Norwood procedure and (2) compare the short- and intermediateterm outcomes of those with postoperative arrhythmia versus those without arrhythmia. We hypothesized that there would be important preoperative and perioperative predictors of postoperative arrhythmias and that postoperative arrhythmias would be associated with poorer outcomes in these fragile infants.

\section{MATERIALS AND METHODS Study Design and Data Collection}

We performed a retrospective cohort study using data from the Pediatric Heart Network SVR Trial, the methods of which have been described. ${ }^{16}$ Briefly, infants with a functionally single ventricle lesion with a single morphologic right ventricle were randomized to undergo a Norwood operation with a modified Blalock-Taussig shunt (MBTS) or a right ventricle-to-pulmonary artery shunt (RVPAS) at 15 clinical centers in North America, with institutional review board approval obtained at each participating center. ${ }^{17}$ Data were collected on a variety of demographic, preoperative, operative, and postoperative factors, including the occurrence of arrhythmias, as well as on a variety of outcomes in the period after the Norwood operation until the stage II operation or 12 months of age, whichever occurred first. In the SVR Trial, only arrhythmias that required medication or other treatment during the post-Norwood hospitalization were captured, with the date of onset being recorded. Tachyarrhythmias included atrial fibrillation, atrial flutter, supraventricular tachycardia, junctional ectopic tachycardia, and ventricular tachycardia. Atrioventricular block included second- or third-degree block, but the information on which type of block was not recorded; episodes of first-degree block were not captured. In regard to therapy, information on pacemakers was collected at the time of pacemaker implantation, but data on medication use were collected only at the time of discharge from the Norwood hospitalization.

All subjects enrolled in the SVR Trial were eligible for this study. We performed separate analyses for tachyarrhythmia and atrioventricular block. We excluded those who died during the Norwood procedure from all analyses. For the specific tachyarrhythmia and atrioventricular block analyses, we further excluded patients with those respective arrhythmias before the Norwood procedure (ie, patients with preoperative tachyarrhythmia were excluded from the tachyarrhythmia analyses and patients with preoperative atrioventricular block were excluded from the atrioventricular block analyses) (Figure 1).

\section{Statistics}

After performing summary statistics describing the prevalence of postoperative tachyarrhythmia and atrioventricular block, we performed risk factor analyses to identify predictors of these arrhythmias during the post-Norwood hospitalization. Univariate analyses were performed on more than 80 demographic, preoperative, and operative factors using logistic regression models. Factors that had a $P$ value of less than .20 and were thought to be clinically relevant were then used as candidate predictors in the stepwise model selection process to construct the multivariable models (Appendix 1). In addition, nonlinearly associated continuous variables identified by generalized additive modeling were appropriately transformed before use in stepwise selection. Final 


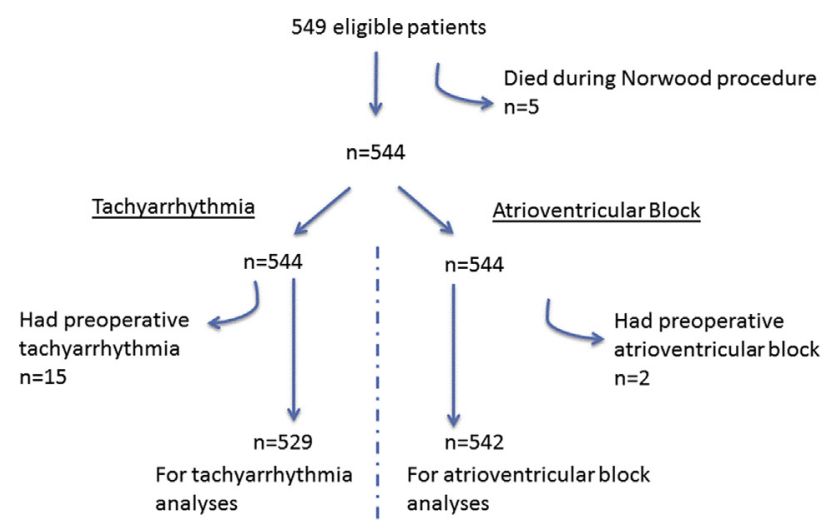

FIGURE 1. Selection of subjects from the SVR Trial.

multivariable logistic regression models include all predictors with $P$ values less than .05 , and model selection results were confirmed via a separate bootstrap analysis. Because many variables may be dependent on site, a subsequent analysis was performed by adding site to these models.

Next, we examined the association of tachyarrhythmia or atrioventricular block with short-term and intermediate-term outcomes of interest. Short-term outcomes included total duration of ventilation (days) and length of hospital stay (days) after the Norwood procedure, excluding those who died or received a heart transplant during the Norwood hospitalization. For the models examining duration of ventilation, we included only those cases in which the onset of arrhythmia occurred before the date of initial extubation. The ventilation days and hospital length of stay were log transformed (with natural base) to attain an approximately normal distribution. Multivariable linear regression analyses were then performed to inform final adjusted models for the relationship between these 2 short-term outcomes and the occurrence of tachyarrhythmia or atrioventricular block, while controlling for covariates determined from a review of previously published studies or from univariate linear regression of the variables in Appendix 1. The covariates included were gestational age ( $<37$ vs $\geq 37$ weeks), presence of genetic syndrome, age at time of Norwood procedure, race (white, black, other), gender, shunt type received, anatomic subtype (aortic stenosis/mitral stenosis and related diagnoses), prenatal diagnosis, total support time during the Norwood procedure (total time on cardiopulmonary bypass), ultrafiltration during or after Norwood procedure, use of extracorporeal membrane oxygenation during the Norwood procedure, presence of postoperative moderate/severe tricuspid regurgitation by echocardiography, and center volume $(\leq 15,16-20,21-30,>30$ patients receiving the Norwood procedure per year). For the length of stay analysis for the atrioventricular block cohort, pacemaker implantation also was included as a covariate in the final multivariable model. Pacemaker implantation was not included in the length of ventilation analyses because no patient had pacemaker implantation before the date of initial extubation. Least-squares means are used to report covariate-adjusted number of days.

The intermediate-term outcome of interest was death or transplant before the stage II procedure, including those who died or received a transplant before discharge after the Norwood procedure. The relationship between transplant-free survival since the Norwood procedure and tachyarrhythmia or atrioventricular block was examined using Kaplan-Meier estimation, with censoring at the time of stage II procedure or at 12 months post-Norwood, whichever occurred first. If this relationship was significant, then further analyses with hazard ratios and $P$ values were calculated from Cox proportional-hazards
TABLE 1. Demographics of the 544 patients included in the Single Ventricle Reconstruction Trial

\begin{tabular}{lc}
\hline & $\begin{array}{c}\text { Mean } \pm \text { SD/median } \\
(\mathbf{I Q R}) / \%\end{array}$ \\
\hline $\begin{array}{l}\text { Demographics } \\
\text { Male }\end{array}$ & $340(63)$ \\
Hispanic ethnicity $(\mathrm{N}=535)$ & $101(19)$ \\
Race & \\
$\quad$ White & $432(79)$ \\
Black & $85(16)$ \\
Other & $27(5)$ \\
$\%$ below federal poverty level $(\mathrm{N}=520)$ & $8.93(4.13-17.01)$ \\
Pregnancy and birth characteristics & \\
Prenatal diagnosis & $417(77)$ \\
Gestational age, wk & $38.2 \pm 1.5$ \\
Birth weight, kg & $3.11 \pm 0.53$ \\
Norwood characteristics & \\
Age at Norwood, d & $5(3-7)$ \\
Shunt at end of operation & \\
$\quad$ MBTS & $265(49)$ \\
RVPAS & $279(51)$ \\
Ultrafiltration during or after Norwood & $459(84)$ \\
Other procedures done at time of Norwood & $61(11)$ \\
\hline
\end{tabular}

$S D$, Standard deviation; $I Q R$, interquartile range; $M B T S$, modified Blalock-Taussig shunt; RVPAS, right ventricle-to-pulmonary artery shunt.

regression models. To be consistent with the prior analyses, the same covariates were used in the adjusted Cox proportional-hazards models. The 5 subjects who had a pacemaker implanted during the post-Norwood hospitalization were excluded from the Kaplan-Meier survival analysis of atrioventricular block because of low numbers, but were listed as a separate group in the adjusted Cox proportional-hazards regression analysis. All analyses were conducted with SAS version 9.3 (SAS Institute, Inc, Cary, NC) and R version 3.0.3 (The R Project for Statistical Computing, Auckland, New Zealand).

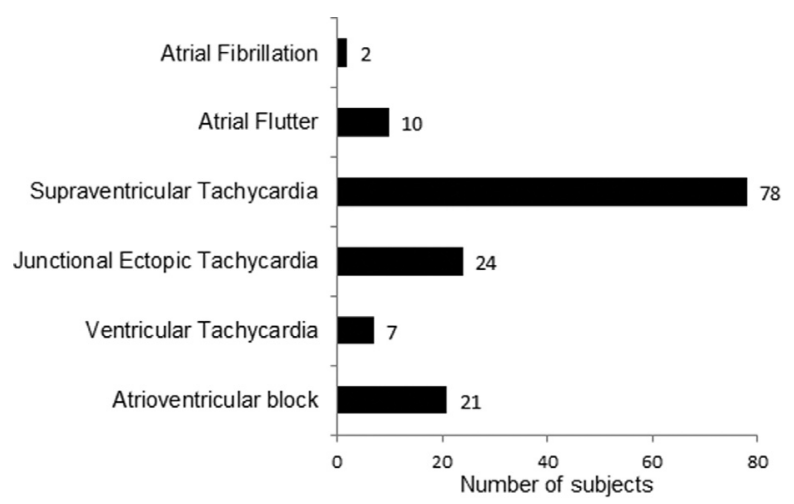

FIGURE 2. Occurrence of postoperative arrhythmias. Among the 544 subjects who received a Norwood procedure in the SVR Trial, 134 had at least 1 postoperative arrhythmia. Eleven subjects had more than 1 type of arrhythmia. Atrioventricular block includes second- and third-degree blocks. 


\section{RESULTS}

Of the 549 patients eligible for the SVR Trial, 544 underwent the Norwood procedure and were available for analysis. Subjects were predominantly male, white, and non-Hispanic. More than $75 \%$ of patients were diagnosed prenatally, and the average gestational age was 38 weeks. The average age at the Norwood procedure was 5 days (Table 1). Among the 544 included subjects, $114(21 \%)$ experienced at least 1 episode of a postoperative tachyarrhythmia, and 21 (4\%) experienced at least 1 episode of postoperative atrioventricular block; 11 subjects had multiple types of arrhythmia (Figure 2).

\section{Tachyarrhythmia}

Among the 529 subjects who did not have a preoperative tachyarrhythmia, 108 had at least 1 episode of a postoperative tachyarrhythmia. After identifying 18 potential factors associated with the development of tachyarrhythmia in the univariate analysis, there were 3 key factors that were significant in the multivariable model. Those with a final shunt type of MBTS had 1.55 times the odds of developing tachyarrhythmia compared with those with an RVPAS (95\% confidence interval [CI], $1.00-2.42 ; P=.05)$, and those who underwent ultrafiltration $(\mathrm{n}=459)$ during or after the Norwood procedure had 3.73 times the odds of tachyarrhythmia compared with those who did not receive ultrafiltration $(95 \% \mathrm{CI}$, 1.17-9.68; $P=.003)$. Although there was no association between the age at time of Norwood and the development of tachyarrhythmia in the first week of life, from 8 to 20 days, the likelihood of developing tachyarrhythmia decreased gradually but significantly each day $0.76 \quad(95 \% \quad \mathrm{CI}, \quad 0.61-0.96)$. There were

TABLE 2. Factors associated with development of tachyarrhythmia or atrioventricular block after the Norwood procedure, adjusted for site

\begin{tabular}{|c|c|c|}
\hline & OR $(95 \%$ CI $)$ & $P$ value \\
\hline \multicolumn{3}{|l|}{ Tachyarrhythmia } \\
\hline \multicolumn{3}{|l|}{ Final shunt type } \\
\hline MBTS & $1.49(0.96-2.32)$ & .08 \\
\hline RVPAS & ref & \\
\hline \multicolumn{3}{|l|}{ Age at Norwood procedure* } \\
\hline $\begin{array}{c}\text { Age at Norwood } \leq 7 \mathrm{~d}, \\
\text { every } 1-\mathrm{d} \text { increase }\end{array}$ & $1.01(0.88-1.15)$ & .94 \\
\hline $\begin{array}{c}\text { Age at Norwood 8-20 d, } \\
\text { every } 1-\mathrm{d} \text { increase }\end{array}$ & $0.77(0.56-1.01)$ & .07 \\
\hline \multicolumn{3}{|l|}{ Atrioventricular block } \\
\hline $\begin{array}{l}\text { Other procedures done at } \\
\text { time of Norwood }\end{array}$ & $5.06(1.81-13.38)$ & .001 \\
\hline
\end{tabular}

TABLE 3. Association with postoperative tachyarrhythmia and atrioventricular block with length of stay and ventilation time (days)

\begin{tabular}{|c|c|c|c|c|}
\hline & $\begin{array}{c}\text { Unadjusted } \\
\text { least-squares } \\
\text { means, } \\
\text { d }(95 \% \text { CI) } \\
\end{array}$ & $\begin{array}{c}P \\
\text { value }\end{array}$ & $\begin{array}{c}\text { Adjusted } * \\
\text { least-squares } \\
\text { means, } \\
\text { d }(95 \% \text { CI })\end{array}$ & $\begin{array}{c}P \\
\text { value }\end{array}$ \\
\hline \multicolumn{5}{|l|}{ Tachyarrhythmia } \\
\hline \multicolumn{5}{|c|}{ Postoperative length of stay } \\
\hline Tachyarrhythmia & $48(41-55)$ & $<.001$ & $49(43-56)$ & $<.001$ \\
\hline No arrhythmia & $31(28-34)$ & & $31(28-34)$ & \\
\hline \multicolumn{5}{|c|}{ Postoperative ventilation time } \\
\hline Tachyarrhythmia & $26(19-34)$ & $<.001$ & $27(20-34)$ & $<.001$ \\
\hline No arrhythmia & $11(8-13)$ & & $11(8-14)$ & \\
\hline \multicolumn{5}{|l|}{ Atrioventricular block } \\
\hline \multicolumn{5}{|l|}{ Postoperative length of stay } \\
\hline Atrioventricular block & $64(50-79)$ & $<.001$ & $58(42-73)$ & .007 \\
\hline No arrhythmia & $31(28-34)$ & & $32(29-34)$ & \\
\hline \multicolumn{5}{|c|}{ Postoperative ventilation time } \\
\hline Atrioventricular block & $27(15-38)$ & .002 & $26(15-38)$ & .002 \\
\hline No arrhythmia & $11(9-13)$ & & $11(9-13)$ & \\
\hline
\end{tabular}

CI, Confidence interval. * Adjusted for gestational age, presence of genetic syndrome age at time of Norwood procedure, race, gender, shunt type received, anatomy subtype, prenatal diagnosis, total support time during the Norwood procedure, ultrafiltration during or after Norwood procedure, use of extracorporeal membrane oxygenation during the Norwood procedure, presence of postoperative moderate/ severe tricuspid regurgitation by echocardiography, and center volume.

insufficient data beyond 20 days of age. When site was added to the model (Table 2), there were small changes in the estimates for MBTS, RVPAS, and age at time of Norwood, although the $P$ values for MBTS and RVPAS did exceed .05 at .08 and .07 , respectively. Notably, however, with site in the model the $P$ value for ultrafiltration was .97 , suggesting that ultrafiltration may have been a surrogate for site.

Tachyarrhythmia was significantly associated with shortterm outcomes during the post-Norwood hospitalization. Compared with those without any postoperative arrhythmia, subjects with a tachyarrhythmia had significantly more days on the ventilator and a longer postoperative length of stay (Table 3). However, development of postoperative tachyarrhythmia was not statistically associated with transplant-free survival to stage II procedure (Figure 3, A).

\section{Atrioventricular Block}

Among the 542 subjects who did not have atrioventricular block before the Norwood operation, $21(4 \%)$ had atrioventricular block postoperatively. Of the 8 potential factors identified by univariate analysis as being associated with atrioventricular block, only 1 factor remained in the multivariable model after stepwise regression. Patients with "other procedures done at time of Norwood" had 4.44 times the odds of developing 


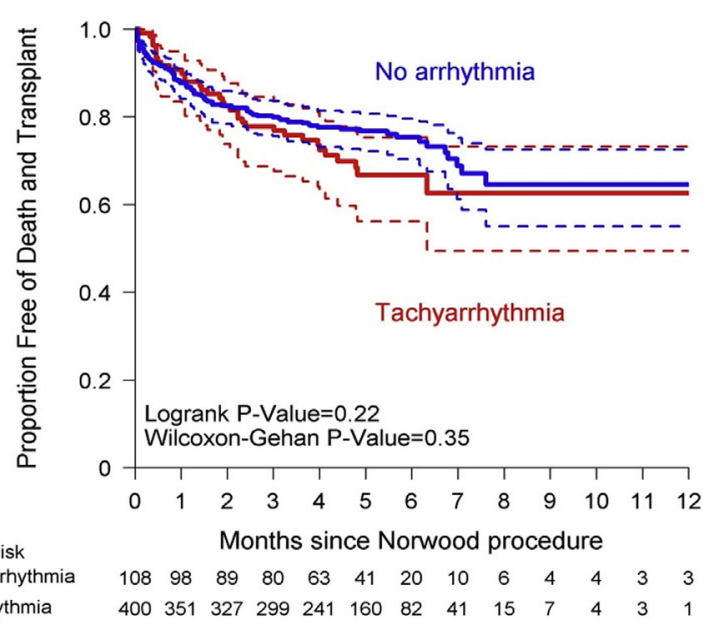

A

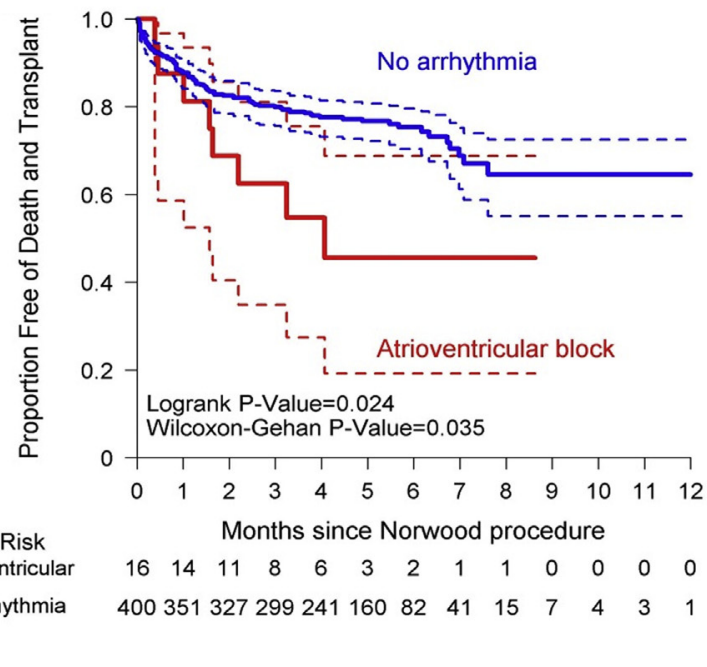

FIGURE 3. Transplant-free survival for subjects with tachyarrhythmia (A) and atrioventricular block (B) versus those without arrhythmia. Patients were censored at the time of stage II procedure. Dashed lines indicate $95 \%$ CIs.

atrioventricular block compared with those who did not have additional procedures $(95 \%$ CI, 1.67-10.92; $P=.002)$. This result did not change significantly when site was added to the model (Table 2). These other procedures included repair of the atrioventricular valve, branch pulmonary arterioplasty, repair of total anomalous pulmonary venous connections, and resection of endofibroelastosis. The odds of developing atrioventricular block were greatest for those undergoing a tricuspid valve procedure (Table 4).

Atrioventricular block was associated with outcomes in both the short and the intermediate term. During the post-Norwood hospitalization, subjects who developed atrioventricular block had significantly more ventilator days and length of stay (Table 3). Of the 21
TABLE 4. Type of procedure associated with development of atrioventricular block after the Norwood procedure

\begin{tabular}{lcc}
\hline \multicolumn{1}{c}{ Atrioventricular block } & OR $(\mathbf{9 5} \% \mathbf{C I})$ & Wald $\boldsymbol{P}^{*}$ \\
\hline & & .001 \\
& & \\
$\begin{array}{l}\text { Tricuspid valve procedure vs no other } \\
\text { procedures done at time of Norwood }\end{array}$ & $9.03(2.39-34.18)$ & \\
Other procedures done at time of Norwood & $3.41(1.12-10.39)$ \\
$\quad$ vs no other procedures done at time of \\
$\quad$ Norwood
\end{tabular}

subjects who had atrioventricular block in the postoperative period, 5 had a pacemaker placed during that hospitalization. The 16 subjects with atrioventricular block without a pacemaker had significantly decreased transplant-free survival to stage II procedure compared with those without any postoperative arrhythmia (Figure 3, B). This association also was seen in the unadjusted Cox proportional hazard regression analysis, with those with atrioventricular block without a pacemaker having 2.26 times the hazard of mortality or transplant before stage II procedure compared with those without an arrhythmia (95\% CI, 1.10-4.65; $P=.03$ ) (Table 5). However, after adding covariates to the model, this finding was no longer significant. Overall, 10 of the 21 subjects with atrioventricular block died or received a transplant and did not survive to the stage II procedure (Appendix 2).

\section{DISCUSSION}

In this large, multicenter study, arrhythmias were common after the Norwood procedure and associated with poorer outcomes. More than $20 \%$ of subjects had a tachyarrhythmia postoperatively, with the presence of MBTS and younger age being potentially important risk factors. Tachyarrhythmias were associated with longer time to extubation and total length of stay, but they were not associated with lower survival. Postoperative second- or third-degree atrioventricular block was less common, occurring in only $4 \%$ of subjects. The only identified risk factor for block was having multiple procedures performed at the time of the Norwood operation, with the greatest risk being in those undergoing a tricuspid valve procedure. Atrioventricular block was significantly associated with increased time to extubation and total length of stay, with a trend toward decreased transplant-free survival to the stage II procedure (Video 1). 
TABLE 5. Hazard ratios for mortality or transplant among patients with atrioventricular block

\begin{tabular}{|c|c|c|c|c|}
\hline & Unadjusted HR $(95 \%$ CI $)$ & Wald $P$ value & Adjusted $*$ HR $(95 \%$ CI $)$ & Wald $P$ value \\
\hline AV block with a pacemaker vs no arrhythmia & $1.31(0.32-5.35)$ & .71 & $1.69(0.33-8.54)$ & .53 \\
\hline AV block without a pacemaker vs no arrhythmia & $2.26(1.10-4.65)$ & .027 & $2.54(0.84-7.69)$ & .098 \\
\hline AV block with a pacemaker vs AV block without a pacemaker & $0.58(0.12-2.76)$ & .49 & $0.66(0.09-4.96)$ & .69 \\
\hline
\end{tabular}

$H R$, Hazard ratio; $C I$, confidence interval; $A V$, atrioventricular. *Adjusted for gestational age, presence of genetic syndrome, age at time of Norwood procedure, race, gender, shunt type received, anatomy subtype, prenatal diagnosis, total support time during the Norwood procedure, ultrafiltration during or after Norwood procedure, use of extracorporeal membrane oxygenation during the Norwood procedure, presence of postoperative moderate/severe tricuspid regurgitation by echocardiography, and center volume.

\section{Tachyarrhythmias}

The findings regarding the development of tachyarrhythmias after the Norwood procedure differ somewhat from 2 prior studies. First, the rate of postoperative tachyarrhythmias in approximately $20 \%$ of subjects is lower than that of recently published single-center studies, which found rates of $50 \%$ (among 66 subjects) ${ }^{18}$ and $35 \%$ (among 98 subjects). ${ }^{19}$ These varying rates may be due to differences in study definition (only cases in which treatment was administered met inclusion in our study) or methods of case ascertainment. Second, there are differences with regard to risk factors for the development of tachyarrhythmias. These prior studies did not find age at Norwood to be a risk factor. With regard to shunt type, there are mixed findings. Whereas in this study, MBTS was potentially associated with the development of tachyarrhythmia, Gist and colleagues ${ }^{19}$ did not find shunt type to be a significant factor, and McFerson and colleagues ${ }^{18}$ found MBTS to have a protective effect. Because our cohort is larger than those of these prior studies, we believe that our study provides the most accurate estimate of risk.

\section{Development and Impact of Arrhythmias Following the Norwood Procedure: A Report from the Pediatric Heart Network}

\begin{tabular}{|c|c|c|}
\hline $\begin{array}{l}\text { Shan Chen } \\
\text { Nicholas Dagincourt } \\
\text { Yaniv Bar-Cohen } \\
\text { Matt Brothers } \\
\text { Nicole Cain } \\
\text { Steve Colan } \\
\text { Richard Czosek }\end{array}$ & $\begin{array}{l}\text { Jamie Decker } \\
\text { David Gamboa } \\
\text { Salim Idriss } \\
\text { Joel Kirsh } \\
\text { Martin LaPage } \\
\text { Richard G. Ohye } \\
\text { Liz Radojewski }\end{array}$ & $\begin{array}{l}\text { Maully Shah } \\
\text { Eric Silver } \\
\text { Anoop Singh } \\
\text { Joel Temple } \\
\text { John Triedman } \\
\text { Jon Kaltman }\end{array}$ \\
\hline \multicolumn{3}{|c|}{ for the Pediatric Heart Network Investigators } \\
\hline
\end{tabular}

VIDEO 1. Dr Matthew Oster explains the key findings and implications from this study. Video available at: http://www.jtcvsonline.org/article/ S0022-5223(16)31486-6/addons.
The findings in this study are in agreement with these prior single studies with regard to the relationship between presence of tachyarrhythmias and outcomes. Tachyarrhythmias are associated with significant morbidity during the postoperative period, particularly a longer length of stay. ${ }^{18}$ However, the increased morbidity does not translate to an increase in mortality. Our study and the 2 smaller studies previously mentioned ${ }^{18,19}$ found no tachyarrhythmia-associated increase in mortality from the time of the Norwood procedure to the time of the stage II procedure. One small, single-center study of 50 patients previously found an association of arrhythmia with mortality before the stage II procedure, but this study included both tachyarrhythmias and bradyarrhythmias, and was limited only to those who survived the initial hospitalization after the Norwood procedure.$^{20}$ It is unclear whether there is no association of tachyarrhythmia with mortality or whether any such association is mitigated with current treatments. This study was not designed to answer such a question, and these results would not suggest any change in the current management of tachyarrhythmias.

\section{Atrioventricular Block}

To our knowledge, this study is the first to investigate the risk factors specifically for the development of atrioventricular block after the Norwood procedure, possibly because of the small numbers of cases seen. A separate study from other investigators using a limited public version of the SVR dataset recently found results similar to ours with regard to the outcomes after atrioventricular block, with minor insignificant differences presumably due to arbitrary methodologic decisions. ${ }^{21}$ Before the SVR study, 1 single-center study examined the impact of atrioventricular block after surgery for singleventricle congenital heart disease. In the 5 of 86 subjects who developed second- or third-degree atrioventricular block after the Norwood operation, Trivedi and colleagues $^{22}$ found a significant association of atrioventricular block with mortality, with none of the 5 subjects surviving to the stage II procedure. In our study, atrioventricular block was associated with decreased transplant-free survival in the Kaplan-Meier analysis 
and the unadjusted Cox proportional-hazards regression analysis, but this finding did not meet significance $(P=.098)$ in the adjusted Cox proportional-hazards regression analysis. This failure to achieve significance may have been due to attempting to include 13 covariates in a model with only 16 subjects with atrioventricular block. Nevertheless, the finding that atrioventricular block may be associated with decreased transplant-free survival is an important one. Previously, it has been shown that $24 \%$ of the deaths in the SVR Trial were due to unexplained causes. ${ }^{23}$ Given the results of our study, one must consider whether untreated or recurrent atrioventricular block may have been a contributing factor in such cases. Compared with patients without any arrhythmia, those with a history of atrioventricular block, but without a pacemaker, had greater than 2 times the hazards of mortality or transplant before the stage II procedure. Of the 9 subjects with atrioventricular block who were discharged to home without a pacemaker, 3 died before the stage II procedure. This risk of increased mortality has similarly been seen in patients with tetralogy of Fallot who had transient complete heart block. ${ }^{24}$ Current guidelines would certainly support "postoperative advanced second or third-degree atrioventricular block that is not expected to resolve or that persists at least 7 days after cardiac surgery" as a class I indication for pacemaker implantation. ${ }^{25}$ However, guidelines also state that pacemaker implantation is not indicated for "postoperative atrioventricular block with return of normal atrioventricular conduction in the otherwise asymptomatic patient." Presumably, unless they were being externally paced in anticipation of a transplant, the 16 subjects in our study who did not receive a pacemaker had a return to normal conduction yet were still at increased risk for mortality or transplant before stage II procedure. With only 5 subjects in our study with atrioventricular block who received a pacemaker ( 2 of whom were discharged to home after the Norwood and subsequently survived to the stage II procedure), our study is underpowered to determine whether pacemaker implantation can decrease mortality, but the consideration of such an intervention would not be unreasonable.

\section{Study Limitations}

This study is not without its limitations. First, only episodes of arrhythmia that were managed with medication or other treatment were included. Because this threshold may vary by center or physician, we may be under- or overdetecting arrhythmia incidence. The mode and timing of treatment may vary by center or physician, thus limiting our ability to make strong conclusions regarding therapies. Second, information regarding the duration or specific treatment of arrhythmias was not recorded. This limits our ability to draw inferences about how certain management options may affect the outcomes. Third, limited clinical detail about atrioventricular block exists in the database, including the degree and duration of block, need for temporary pacing, and timing of resumption of sinus rhythm. There may be important differences in outcomes for second- versus third-degree atrioventricular block that we are unable to discern. Fourth, the rarity of certain events, such as atrioventricular block, may have limited the power to detect important differences in outcomes. Finally, although we found that atrioventricular block may be associated with increased mortality even after controlling for degree of atrioventricular valve insufficiency, we also found that having concomitant procedures such as atrioventricular valve repair may be associated with the development of atrioventricular block. Our study was not powered to distinguish whether mortality associated with atrioventricular block actually may indicate mortality associated with atrioventricular valve repair.

\section{CONCLUSIONS}

Arrhythmias, particularly tachyarrhythmias, are common after the Norwood procedure. MBTS and younger age are potentially associated with the development of tachyarrhythmias, whereas undergoing concomitant procedures with the Norwood are associated with atrioventricular block, particularly procedures including the tricuspid valve. Both types of arrhythmias are associated with greater short-term morbidity, but only atrioventricular block may be associated with increased intermediate-term mortality. Optimal strategies to improve the outcomes for those with atrioventricular block, such as the use of an implantable pacemaker, remain unclear.

\section{Conflict of Interest Statement}

Authors have nothing to disclose with regard to commercial support.

\section{References}

1. Fixler DE, Nembhard WN, Salemi JL, Ethen MK, Canfield MA. Mortality in first 5 years in infants with functional single ventricle born in Texas, 1996 to 2003. Circulation. 2010;121:644-50.

2. Norwood WI, Kirklin JK, Sanders SP. Hypoplastic left heart syndrome: experience with palliative surgery. Am J Cardiol. 1980;45:87-91.

3. Oster ME, Lee KA, Honein MA, Riehle-Colarusso T, Shin M, Correa A. Temporal trends in survival among infants with critical congenital heart defects. Pediatrics. 2013;131:e1502-8.

4. Ohye RG, Sleeper LA, Mahony L, Newburger JW, Pearson GD, Lu M, et al. Comparison of shunt types in the Norwood procedure for single-ventricle lesions. N Engl J Med. 2010;362:1980-92.

5. Balaji S, Daga A, Bradley DJ, Etheridge SP, Law IH, Batra AS, et al. An international multicenter study comparing arrhythmia prevalence between the intracardiac lateral tunnel and the extracardiac conduit type of Fontan operations. $J$ Thorac Cardiovasc Surg. 2014;148:576-81. 
6. Blaufox AD, Sleeper LA, Bradley DJ, Breitbart RE, Hordof A, Kanter RJ, et al. Functional status, heart rate, and rhythm abnormalities in 521 Fontan patients 6 to 18 years of age. J Thorac Cardiovasc Surg. 2008;136:100-7. 107.e1.

7. Bossers SS, Duppen N, Kapusta L, Maan AC, Duim AR, Bogers AJ, et al. Comprehensive rhythm evaluation in a large contemporary Fontan population. Eur J Cardiothorac Surg. 2015;48:833-41.

8. Bouchardy J, Therrien J, Pilote L, Ionescu-Ittu R, Martucci G, Bottega N, et al. Atrial arrhythmias in adults with congenital heart disease. Circulation. 2009;120: 1679-86.

9. Kurer CC, Tanner CS, Norwood WI, Vetter VL. Perioperative arrhythmias after Fontan repair. Circulation. 1990;82:IV190-4.

10. Walsh EP, Cecchin F. Arrhythmias in adult patients with congenital heart disease. Circulation. 2007;115:534-45.

11. Makhoul M, Oster M, Fischbach P, Das S, Deshpande S. Junctional ectopic tachycardia after congenital heart surgery in the current surgical era. Pediatr Cardiol. 2013;34:370-4.

12. Reichlin A, Pretre R, Dave H, Hug MI, Gass M, Balmer C. Postoperative arrhythmia in patients with bidirectional cavopulmonary anastomosis. Eur $J$ Cardiothorac Surg. 2014;45:620-4.

13. Shamszad P, Cabrera AG, Kim JJ, Moffett BS, Graves DE, Heinle JS, et al. Perioperative atrial tachycardia is associated with increased mortality in infants undergoing cardiac surgery. J Thorac Cardiovasc Surg. 2012;144:396-401.

14. Smith AH, Owen J, Borgman KY, Fish FA, Kannankeril PJ. Relation of milrinone after surgery for congenital heart disease to significant postoperative tachyarrhythmias. Am J Cardiol. 2011;108:1620-4.

15. Tabbutt S, Ghanayem N, Ravishankar C, Sleeper LA, Cooper DS, Frank DU, et al. Risk factors for hospital morbidity and mortality after the Norwood procedure: a report from the Pediatric Heart Network Single Ventricle Reconstruction trial. J Thorac Cardiovasc Surg. 2012;144:882-5.

16. Ohye RG, Devaney EJ, Hirsch JC, Bove EL. The modified Blalock-Taussig shunt versus the right ventricle-to-pulmonary artery conduit for the Norwood procedure. Pediatr Cardiol. 2007;28:122-5.

17. Ohye RG, Gaynor JW, Ghanayem NS, Goldberg CS, Laussen PC, Frommelt PC, et al. Design and rationale of a randomized trial comparing the Blalock-Taussig and right ventricle-pulmonary artery shunts in the Norwood procedure. J Thorac Cardiovasc Surg. 2008;136:968-75.
18. McFerson MC, McCanta AC, Pan Z, Collins KK, Jaggers J, da Cruz EM, et al Tachyarrhythmias after the Norwood procedure: relationship and effect of vasoactive agents. Pediatr Cardiol. 2014;35:668-75.

19. Gist KM, Schuchardt EL, Moroze MK, Kaufman J, Cruz E, Campbell DN, et al Tachyarrhythmia following Norwood operation: a single-center experience. World J Pediatr Congenit Heart Surg. 2014;5:206-10.

20. Simsic JM, Bradley SM, Stroud MR, Atz AM. Risk factors for interstage death after the Norwood procedure. Pediatr Cardiol. 2005;26: 400-3.

21. Mah DY, Cheng H, Alexander ME, Sleeper L, Newburger JW, Del Nido PJ, et al Heart block following stage 1 palliation of hypoplastic left heart syndrome. $J$ Thorac Cardiovasc Surg. 2016;152:189-94.

22. Trivedi B, Smith PB, Barker PC, Jaggers J, Lodge AJ, Kanter RJ. Arrhythmias in patients with hypoplastic left heart syndrome. Am Heart J. 2011;161: 138-44.

23. Ohye RG, Schonbeck JV, Eghtesady P, Laussen PC, Pizarro C, Shrader P, et al Cause, timing, and location of death in the Single Ventricle Reconstruction trial J Thorac Cardiovasc Surg. 2012;144:907-14.

24. Hokanson JS, Moller JH. Significance of early transient complete heart block as a predictor of sudden death late after operative correction of tetralogy of Fallot. Am J Cardiol. 2001;87:1271-7.

25. Epstein AE, DiMarco JP, Ellenbogen KA, Estes NA III, Freedman RA, Gettes LS, et al. ACC/AHA/HRS 2008 Guidelines for Device-Based Therapy of Cardiac Rhythm Abnormalities: a report of the American College of Cardiology/American Heart Association Task Force on Practice Guidelines (Writing Committee to Revise the ACC/AHA/NASPE 2002 Guideline Update for Implantation of Cardiac Pacemakers and Antiarrhythmia Devices): developed in collaboration with the American Association for Thoracic Surgery and Society of Thoracic Surgeons. Circulation. 2008;117:e350-408.

Key Words: arrhythmia, atrioventricular block, mortality, Norwood, outcomes, single ventricle, tachyarrhythmia 
APPENDIX 1. List of candidate predictors for tachyarrhythmia and atrioventricular block

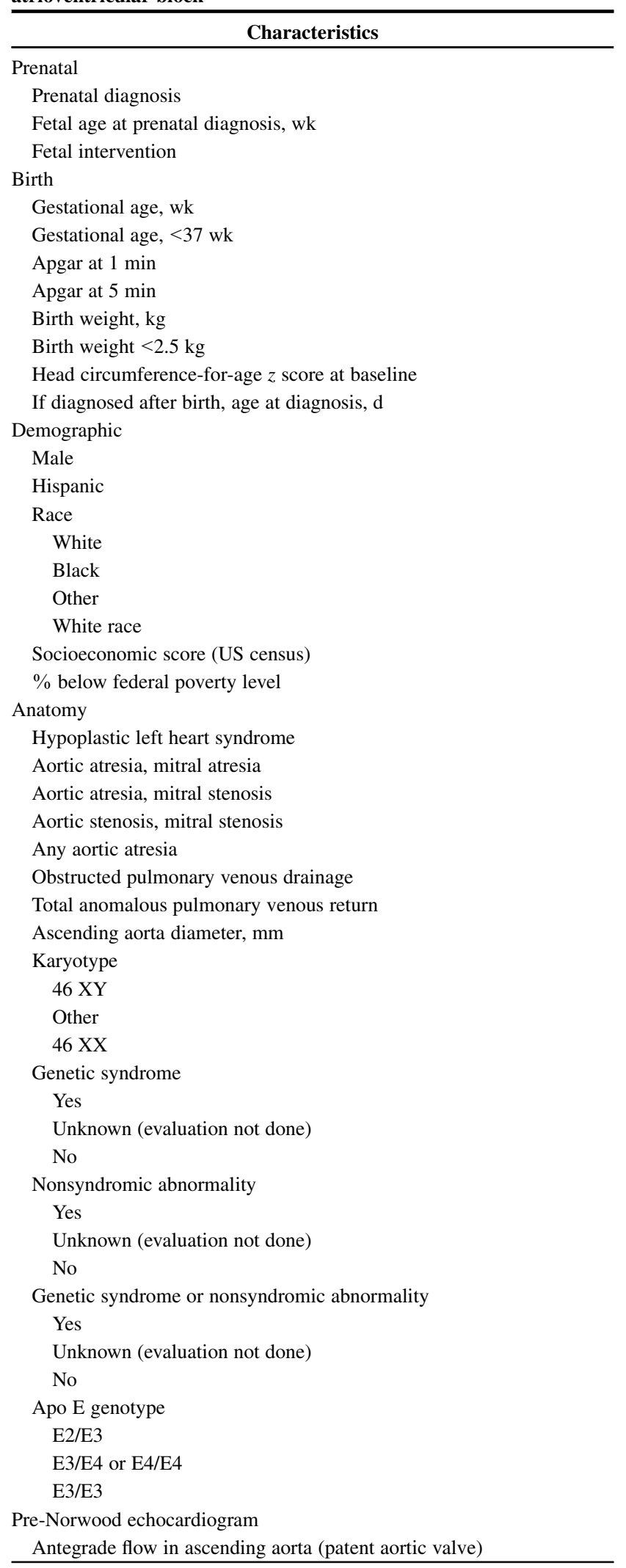

APPENDIX 1. Continued

\section{Characteristics}

Atrial septal defect mean Doppler gradient, $\mathrm{mm} \mathrm{Hg}$

Right ventricular ejection fraction, $\%$

Fractional area change

Left ventricle present

Moderate/severe mitral regurgitation

Moderate/severe tricuspid regurgitation

Moderate/severe aortic valve regurgitation

Preoperative

Median highest lactate, $\mathrm{mmol} / \mathrm{L}$

Mechanical ventilation

Inhaled gases $\mathrm{CO} 2$

Inhaled gases $\mathrm{N} 2$

Pre-Norwood apnea

Pre-Norwood shock

Pre-Norwood respiratory failure

Pre-Norwood metabolic acidosis

Pre-Norwood catheter intervention

Pre-Norwood catheter interventions

Pre-Norwood cardiac surgery

Pre-Norwood noncardiac surgery

Pre-Norwood any surgery

Pre-Norwood total surgeries

Pre-Norwood complications

Pre-Norwood complications

Stage 1

Age at Norwood, $d$

Shunt at end of operation

MBTS

RVPAS

Cross over

Total crossclamp time, min

Norwood perfusion type

Deep hypothermic circulatory arrest only

Regional cerebral perfusion and deep hypothermic circulatory arrest time $\leq 10 \mathrm{~min}$

Regional cerebral perfusion deep hypothermic circulatory arrest with deep hypothermic circulatory arrest time $>10 \mathrm{~min}$

Total support time, min

Total bypass time, min (excludes RCP time)

Total deep hypothermic circulatory arrest time, min

Total regional cerebral perfusion time, $\mathrm{min}$

Regional cerebral perfusion flow, $\mathrm{mL} / \mathrm{kg} / \mathrm{min}$

Lowest temperature

Lowest hematocrit, \%

Ultrafiltration during or after Norwood

Steroids

Aprotinin

a-blockade

Extracorporeal membrane oxygenation used in operating room

Type of arch reconstruction

Classic arch reconstruction

Direct pulmonary artery anastomosis to arch

Coarctectomy

Patch

Origin - polytetrafluoroethylene graft 


\begin{tabular}{l}
\hline \multicolumn{1}{c}{ Characteristics } \\
\hline Innominate \\
Subclavian \\
Common carotid \\
Aorta \\
Right ventricle \\
Other procedures done at time of Norwood \\
Open sternum on day of Norwood \\
Open sternum after Norwood \\
Surgeon Norwood volume \\
Surgeon Norwood volume $\leq 5 / y$ \\
Surgeon Norwood volume \\
$\leq 5 / y$ \\
$\leq 10 / y$ \\
$\leq 15 / y$ \\
$>15 / y$ \\
Center volume \\
Center volume \\
$\leq 15 / y$ \\
$\leq 20 / y$ \\
$\leq 30 / y$ \\
$>30 / y$
\end{tabular}

APPENDIX 2. Outcomes for patients who developed second- or third-degree atrioventricular block after the Norwood procedure, separated by history of having a pacemaker placed

\begin{tabular}{|c|c|c|c|c|}
\hline Patient & $\begin{array}{c}\text { Days post-Norwood } \\
\text { when AV block } \\
\text { first occurred }\end{array}$ & $\begin{array}{c}\text { Days post-Norwood } \\
\text { when pacemaker } \\
\text { placed } \\
\end{array}$ & $\begin{array}{l}\text { Length of stay } \\
\text { post-Norwood }\end{array}$ & Outcome (cause of death, where appropriate) \\
\hline 1 & 62 & 76 & 268 & Transplant during post-Norwood hospitalization \\
\hline 2 & 0 & 9 & 49 & Transplant during post-Norwood hospitalization \\
\hline 3 & 27 & 33 & 200 & Remained inpatient until stage II \\
\hline 4 & 8 & 15 & 29 & Survived to stage II \\
\hline 5 & 0 & 41 & 57 & Survived to stage II \\
\hline 6 & 6 & & 12 & Transplant during post-Norwood hospitalization \\
\hline 7 & 0 & & 30 & $\begin{array}{l}\text { Death during post-Norwood hospitalization (noncardiac, complex/multisystem } \\
\text { organ failure due to infection) }\end{array}$ \\
\hline 8 & 35 & & 46 & Transplant during post-Norwood hospitalization \\
\hline 9 & 0 & & 11 & $\begin{array}{l}\text { Death during post-Norwood hospitalization (cardiac, surgical complication, } \\
\text { low cardiac output) }\end{array}$ \\
\hline 10 & 5 & & 49 & $\begin{array}{l}\text { Death during post-Norwood hospitalization (cardiac, surgical complication, } \\
\text { right ventricular dysfunction) }\end{array}$ \\
\hline 11 & 0 & & 207 & Remained inpatient until stage II \\
\hline 12 & 0 & & 127 & Remained inpatient until stage II \\
\hline 13 & 0 & & 44 & $\begin{array}{l}\text { Death before stage II (noncardiac, infectious, severe necrotizing staph } \\
\text { aureus pneumonia) }\end{array}$ \\
\hline 14 & 0 & & 26 & Death before stage II (noncardiac, infectious, sepsis) \\
\hline 15 & 0 & & 34 & Death before stage II (noncardiac, infectious, gastritis, and diarrhea) \\
\hline 16 & 0 & & 28 & Survived to stage II \\
\hline 17 & 0 & & 19 & Survived to stage II \\
\hline 18 & 0 & & 22 & Survived to stage II \\
\hline 19 & 7 & & 28 & Survived to stage II \\
\hline 20 & 9 & & 51 & Survived to stage II \\
\hline 21 & 0 & & 16 & Survived to stage II \\
\hline
\end{tabular}

$A V$, Atrioventricular. 